\title{
Lifante Vidal, Isabel. Argumentación e interpretación jurídica. Escepticismo, intencionalismo y constructivismo. Valencia, Tirant Lo Blanch, 2018.
}

\author{
Ilsse Carolina Torres Ortega \\ Departamento de Estudios Sociopolíticos y Jurídicos \\ Instituto Tecnológico y de Estudios Superiores de Occidente (ITESO)
}

Fecha de recepción 23/05/2018 I De publicación: 27/06/2017

Hacer una reseña sobre un libro es una labor que, pese a su aparente sencillez, es en el fondo harto compleja. Esa complejidad creo que radica en la necesidad de encontrar un buen modelo del género y en adoptar la perspectiva adecuada para desarrollarlo en el caso concreto. Seguramente, aquella persona que decide emprender tan delicada tarea ha de evitar, principalmente, dos grandes tentaciones. Por un lado, la de acabar convirtiendo la reseña de un trabajo en una retahíla de cumplidos acerca de la importancia del mismo, eso en el mejor de los casos, y en el peor, en un ejercicio escrito de mera adulación. Y, por otro lado, la tentación de emprender una tarea de "resumista" del trabajo que presente de forma descontextualizada las ideas $y$, en ese sentido, no haga justicia -no saque la mejor luz- al trabajo de que se trate. Por ello, me parece que, evitando tales tentaciones, lo que realmente ha de buscarse a través de una reseña es presentar adecuadamente algunas de las ideas centrales que el autor presenta en dicha obra, y ello con el objetivo de despertar el interés de potenciales lectores $\mathrm{y}$ proporcionarles algunas "guías" para emprender la lectura. En lo que sigue, intentaré lograr esto.

La presente reseña consta de dos partes. En la primera parte, haré una referencia sistemática sobre cómo está organizado el libro y sobre el contenido de los distintos capítulos. En una segunda parte, me propongo articular una serie de presupuestos de la teoría de la interpretación en el ámbito del Derecho de la autora, como una labor de reconstrucción a partir de las páginas del libro.

$* * * * *$

Por lo que corresponde a la primera parte, el libro en cuestión tiene como propósito, en palabras de la autora "defender una concepción constructivista o dependiente de valores de la interpretación jurídica y mostrar su superioridad 
frente a concepciones rivales"1. Para avanzar en ello, la autora divide su argumentación en cinco capítulos.

En el primero de ellos explora el concepto de interpretación y los distintos problemas que dicha conceptualización plantea (aquellos derivados de la ambigüedad del término; la falta de consenso sobre el objeto de la interpretación; el problema acerca de quién interpreta; las reflexiones en torno a los argumentos interpretativos, entre otros), ello para avanzar en dicha tarea e identificar las distintas concepciones de la interpretación jurídica en la teoría del Derecho.

De esta manera, utiliza dos criterios para identificar las concepciones de la interpretación, uno según el alcance de la actividad interpretativa (incluye la contraposición: interpretación de la ley e interpretación del Derecho en su conjunto, y la de interpretación en abstracto y en concreto) y otro que diferencia las concepciones atendiendo a cuál es el papel de los argumentos interpretativos (incluye las teorías escépticas, las cognoscitivas que, a su vez, contienen a las teorías literalistas y las intencionalistas- y las consideradas "intermedias" o constructivistas).

En el segundo capítulo aborda la concepción del escepticismo interpretativo, en primer lugar, en el pensamiento de Hans Kelsen, bajo las tesis del

${ }^{1}$ Lifante Vidal, Isabel. Argumentación e interpretación jurídica. Escepticismo, intencionalismo y constructivismo, Valencia, Tirant lo Blanch, 2018, p. 11. positivismo normativista, la teoría prescriptivista del Derecho y el emotivismo ético radical. Por otra parte, analiza también la propuesta de un escepticismo interpretativo moderado de Riccardo Guastini, destacando la tesis del segregacionismo discursivo (hay una distinción clara entre el discurso descriptivo y el prescriptivo) y la tesis del escepticismo moderado (que viene a desarrollar la idea de una omnipresente indeterminación del Derecho, aun con la existencia de significados previos a la interpretación).

En el tercer capítulo, la autora analiza la concepción intencionalista interpretativa, explorando las ideas centrales al respecto en los trabajos de Andrei Marmor y de Joseph Raz. El objetivo principal es poner de manifiesto la oscuridad y la ambigüedad de la distinción entre concepciones subjetivas y objetivas de la intención, así como los problemas a la hora de dar cuenta de la interpretación en el ámbito jurídico desde una concepción del Derecho como modelo comunicativo (esto es, como un mensaje de la autoridad).

En el capítulo cuarto, Lifante presenta el constructivismo interpretativo, centrándose en el pensamiento de Ronald Dworkin, cuyos presupuestos son centralmente compartidos en la corriente post-positivista. Dworkin entiende que el Derecho ha de ser comprendido como práctica social y como práctica de naturaleza 
interpretativa; propone que al interpretar ha de reestructurarse la práctica a la luz de los objetivos planteados en una primera reflexión sobre qué hace valioso al Derecho.

Finalmente, en el quinto capítulo la autora hace un balance crítico sobre su propia postura, mostrando cómo los presupuestos teóricoconceptuales del Derecho van a determinar si la actividad interpretativa nos embarca en una tarea descriptiva o si nos ha de llevar también, de alguna manera, a una tarea prescriptiva reconstructiva- que habla de la práctica, pero que también la dirige.

$* * * * *$

En esta segunda parte, intentaré hacer un trabajo de reconstrucción similar al que la autora ha hecho en su libro con otros teóricos del Derecho; para ello voy a enunciar - de forma que pretendo ordenada y articulada- los presupuestos que subyacen a la teoría normativa de la interpretación en el ámbito del Derecho de Isabel Lifante:

1- La autora se adhiere a la idea del Derecho como práctica social que pretende alcanzar $\mathrm{y}$ desarrollar determinados fines valiosos. Esta manera de ver el Derecho dibuja una aproximación muy diferente de aquella que lo entiende únicamente como un sistema de normas (el normativismo). Tal y como señala Atienza, en esta idea podemos identificar tres componentes:
(1) una concepción dinámica del Derecho; (2) la distinción de una dimensión autoritativa y otra axiológica -gozando esta última de cierta preeminencia-; y (3) la necesaria vinculación de la práctica jurídica con valores morales objetivos $^{2}$.

2- Además de la aproximación al Derecho como práctica social, la autora se sitúa en lo que se conoce como una concepción del Derecho nopositivista -concretamente postpositivista $\mathrm{o}$ constitucionalista. La asunción de tal perspectiva a la hora de dar cuenta del Derecho le lleva a alejarse de la tesis de la inexistencia de una conexión necesaria entre el Derecho y la moral cuando se trata de dar cuenta del Derecho en contextos justificativos, esto es, cuando ponemos el acento en su dimensión práctica que pretende guiar la conducta y someterla a juicio crítico y, en su caso, a consecuencias tales como la sanción.

3- En efecto, esta concepción que subyace a la teoría de la interpretación de la autora admite que existe una conexión necesaria entre el Derecho y la moral por lo menos en ciertos casos, centralmente, cuando planteamos la necesidad de justificar racionalmente -esto es, mediante argumentos en un discurso intersubjetivo- las normas, las instituciones, las decisiones jurídicas en general y los actos realizados a la luz de todas ellas; algo que es una exigencia fundamental en

${ }^{2}$ Atienza, Manuel, Filosofía del Derecho y transformación social, Madrid, Editorial Trotta, 2017, p. 35. 
sociedades que se pretenden constitucionales y democráticas.

4- La organización de estas sociedades se inspira en el ideal regulativo del "Estado constitucional de Derecho", como ideal que aspira al desarrollo y protección de los derechos fundamentales en un contexto en el que el poder normativo y el ejercicio de la fuerza estén sometido a control racional. En el escenario institucional propio de este modelo de sociedad se subraya la doble dimensión del Derecho: una valorativa (la racionalidad práctica) y una autoritativa (el imperio de la ley).

5- Hablar de la dimensión valorativa nos lleva necesariamente a plantearnos el problema de la concepción de los valores. Lifante no es escéptica acerca de la posibilidad de discutir racionalmente acerca de valores y, además, ese racionalismo en materia valorativa le lleva a suscribir la posición objetivista (concretamente, un objetivismo mínimo en la dimensión metaética). Esto le permite defender que los fines a los que tiende la práctica social del Derecho y los valores que protege no son fines ni valores puramente contingentes, sino que tal práctica incorpora y trata de proteger ciertos valores que, a la luz de los argumentos, podemos entender que son mejores que otros (i.e. racionalmente mejor fundamentados).
6- Así concebido, y en la medida en que atienda y satisfaga esos valores, tendremos razones para sostener que el Derecho será algo valioso y cumplirá su pretensión de legitimar las conductas y estados de cosas que a su luz se lleven a cabo. Estamos en el escenario propio de lo que se denomina razón práctica (Derecho, moral y política) y las tesis que respecto de este ámbito suscribe la concepción asumida por la autora son tanto la unidad del razonamiento práctico como la pretensión de corrección erigida por la propia práctica.

7- Ahora bien, el Derecho es también, y muy especialmente, una institución autoritativa (aunque la fundamentación última de esta dimensión se encuentre en la anterior, puesto que las razones autoritativas, para ser legítimas $\mathrm{y}$ operar en el razonamiento jurídico, necesitan estar fundamentadas en razones sustantivas). Así, los enunciados jurídicos $\mathrm{o}$ fuentes formales del Derecho, las autoridades y los órganos de gobierno tienen un papel preponderante en las actividades que se desarrollan en el marco de la práctica jurídica. El Derecho no es pura razón sustantiva, sino que hay decisiones jurídicamente últimas.

8- Pues bien, así concebido el Derecho como práctica social con una doble dimensión, Lifante subraya que en ella tiene un lugar central la argumentación (obviamente, el Derecho no es sólo argumentación, sino que, como señalaba 
antes, incluye decisiones últimas no revisables y también la fuerza). Cuando la autora habla de argumentar está refiriéndose específicamente a la actividad de formular argumentos a favor o en contra de algo; esta actividad argumentativa, a su vez, aparece contextualizada en escenarios prácticos (esto es, razones en contra o a favor de hacer algo o sobre lo que debe, podría o puede hacerse ${ }^{3}$ ), admitiendo la posibilidad de evaluar la corrección de tales argumentaciones (en conformidad con el presupuesto al que me referí en el punto 5).

9- En cuanto a la actividad interpretativa, la autora deja claro que hay casos en los que, revisadas todas las razones (sustantivas $\mathrm{y}$ autoritativas), no se plantean serias dudas acerca del significado de una disposición jurídica; casos en los que la interpretación literal de la ley o el recurso a la voluntad del legislador logran ofrecer una interpretación justificada (argumentos de las razones autoritativas). No obstante, ante las dudas -no poco frecuentes- acerca de la atribución de significado, se pone de manifiesto que la interpretación es una actividad argumentativa que se encuentra inserta en una práctica en la que operan criterios evaluativos de corrección (niega así el escepticismo interpretativo).

3 MacCormick, Neil. "Argumentación e interpretación en el Derecho", trad. J. L. Fabra y L. S. Guevara, Doxa. Cuadernos de filosofía del Derecho, número 33, 2010, pp.65-78.
10- La labor del intérprete no sólo se limita a un acto puramente cognitivo o volitivo; desde esta perspectiva, intentar guiar -corregir- la interpretación sería extremadamente limitado, restándole legitimidad. La descripción de la práctica interpretativa como una práctica inmersa en valores y fines, en cambio, permite guiar la labor del intérprete hacia la generación de interpretaciones que desarrollen tales valores $y$ fines en la mayor medida posible (en definitiva, vemos aquí una adhesión al constructivismo interpretativo).

11- Subrayar el lugar central que en la práctica jurídica interpretativa tienen las razones autoritativas nos hace no perder de vista el carácter de labor no inventiva que tiene la actividad interpretativa. Los materiales jurídicos definen el marco de la actividad, puesto que, desde la concepción constructivista suscrita por la autora, la interpretación como actividad valorativa desarrolla ese proceso de reconstrucción antes mencionado a partir de dichos materiales.

12- Dados estos presupuestos, y pensando en un escenario en el que distintas posibilidades interpretativas están presentes, el interés teórico de la autora no es puramente descriptivo, sino también normativo, por lo que la cuestión central de su investigación es cómo se debe interpretar el Derecho o, más precisamente, en qué consiste una interpretación justificada en el ámbito jurídico. La autora defiende, así, una teoría normativa de la 
interpretación en el ámbito del Derecho que nos remite al ámbito de la razón práctica que conecta Derecho, moral y política.

13- Lifante sostiene que la interpretación jurídica no se caracteriza únicamente por su objeto (normas, disposiciones jurídicas, etc.), sino también por ayudar a conformar el propio Derecho. En este sentido, el intérprete es, necesariamente, un participante y, en cuanto tal, comparte los valores que el Derecho pretende desarrollar y está comprometido con la mejora del Derecho. Esto quiere decir que el intérprete ha de guiar su labor hacia este objetivo de mejora, lo que implica que ante dos posibles interpretaciones prima facie asumibles, la que elija habrá de ser la que mejor realice los valores del Derecho, aquellos que dotan al mismo de su mejor fundamento crítico. 


\section{REFERENCIAS}

ATIENZA, Manuel (2017): Filosofía del Derecho y transformación social, Trotta, Madrid.

LIFANTE VIDAL, Isabel (2018): Argumentación e interpretación jurídica. Escepticismo, intencionalismo y constructivismo, Tirant lo Blanch, Valencia.
MACCORMICK, Neil (2010): “Argumentación e interpretación en el Derecho", trad. J.L. Fabra y L.S. Guevara, en Doxa. Cuadernos de filosofía del Derecho, $\mathrm{n}^{\circ}$ 33 , pp. 65-78. 